can market in September, 1963, following a third definitive writing conference. It is the second revision which is the subject of this review.

To appreciate the significance of this remarkable tour de force both for British and American education it is essential to understand routes by which British school biology has reached its present scope and acquired its present character. At least 80,000 boys and girls enter for biology each year at the Ordinary Level of the General Certificate of Education in England and Wales, and thus exceed the entries for any other single science by some 18,000; and three-quarters of these entrants are girls. The ratio of degrees awarded each year in biological subjects to passes each year at Advanced Level and Ordinary Level is approximately 1 to 7.5 and 1 to 94 respectively. Thus the bulk of school biology is not concerned with either entry into university or university type of work, a fact which has to be balanced against the currently fashionable idea that mathematics, physies and chemistry is the only proper intellectual diet for science sixth formers. Another striking fact is the extent to which Advanced Level examination questions are predominanty descriptive and out of phase with contemporary biological thought and tmphasis.

In this situation the moves afoot to re-align school biology are nationally important, vigorous and extensive as a study of the publications of the past three or four years shows well. Britain's 'gadgetry' is excellent, several stimulating schemes for reform are in existence, and uationally important bodies provide several types of facilities to teachers. The needs are to raise the standard of intellectual rigour of biology by modernization, shift of emphasis and reduction of study of too much dead material. In the long run new forms of training for teachers will be necessary, a far closer co-operation between school and university called for and a big increase in the supply of laboratory technicians in the schools at a far greater cost than now. Yet no real change is possible until the examination boards alter their policies and syllabuses and type of examination.

The American problem is essentially like Britain's, and has been stressed in urgency by reaction in the 1950's to Soviet performances. This is why the publication under review, running as it does into thirty-eight volumes, is bound to have a world-wide impact.

The American panels first set out nine basic biological concepts all of current research interest:

Evolution, diversity of animal and plant life in relation to unity of phylogenetical patterns, genetic continuity, relation of organism to environment, relation of structure to function, biological roots of behaviour, homoeostasis, and science as inquiry. Intellectual history of biological concepts is woven into the treatment.

From this three courses were prepared, each comprising three text-books to cover a yearly course and containing a greater volume of material than the pupil is expected to remember. Each course also has three laboratory manuals, one for each text-book and forming the main course to which the reading in the texts is a background. There are also three teacher's handbooks with each course.

The 'Green' course starts with ecology and relationships and works up to biochemistry; the 'Blue' course empha. size biochemistry and works by stages towards ecology, while the 'Yellow' course begins with cytology and works in two directions from it, one towards biochemistry and the other towards ecology via various levels like physiology and systematic biology. 70 per cent of the matter is common to all three courses. The level of presentation is directed at the 16-18-year-old pupil.

In assessing the extent to which these works achieve their aims it is necessary to realize the completeness and the revivifying effects of the break with traditional methods and thoughts. The practical work impels the course on its way and is not didectically presented but is introduced as a form of research. The ingenuity of the practical methods is excellent. In addition, supporting volumes set up two new themes. One is the laboratory block by which single or small teams of pupils are given a stretch of six weeks full-time laboratory work. "During the next six weeks we want you to work like a scientist" is the opening sentence of the block. The second new theme is the provision of volumes written by research biologists stating 150 research problems within the capacity of the pupils and to which the answers are as yet unknown. Throughout, the style of writing is exciting and I myself have tested the effects of it on my own pupils and am convinced of its adequacy for its avowed purpose. The quality of the illustrations is not high; but it has to be remembered that one is seeing an interim version, not a final commercial production.

The success of this splendid experiment will be measured in proportion to its effectiveness in stimulating and shifting opinion outside the United States. [Ses also Nature, 194,$242 ; 1962$.$] \quad I. M. J. Kramer$

\section{PHYSICO-CHEMICAL TECHNIQUES IN PHYSIOLOGY}

\section{Physical Techniques in Biological Research}

Edited by William L. Nastuk. Vol. 4: Special Methods. Pp. xiii 410. (New York: Academic Press, Inc.; London: Academic Press, Inc. (London), Ltd., 1962.) 13 dollars.

$\mathrm{T}$ HE previous volumes of this series wore concerned with optical techniques (1955), physico-chemical techniques (1956), physical methods of observation of cells and tissues (1956).

Now, after an interval of six years, a new volume with a new editor, dealing with "Special Methods", has appeared. This is concerned with various specialized physico-chemical techniques with applications in physiology. S. Chien and M. I. Gregersen have written a comprehensive monograph on the determination of the volumes of body fluids which will be invaluable to all who are concerned with this. E. M. Renkin writes on the techniques of vascular perfusion-a method which has extensive uses in studying the functions of different tissues or organs. A more physico-chemical parameter, which is of considerable interest in connexion with tissue metabolism and has importance in radiotherapy, is the oxygen tension. P. W. Davies discusses the use of oxygen cathodes of various types in these determinations. It appears that successful determinations can be made by using the ability of oxygen to depolarize cathodes, the extent of depolarization depending on the diffusion of oxygen in the medium. A. B. Otis describes physical techniques used in the examination of respirationmainly involving the analysis of the gases involved. $M$. Margoshes describes recent studies of flame photometrya method of determining certain metals which has been greatly refined by the more exact control of temperature. Finally, W. T. Fry and F. Dunn contribute a lengthy monograph on ultrasound, which deals very comprehensively with the methods of producing ultrasound and its physical properties. This section contains much more information than most biological users of ultrasounds could be expected to require. Certain biological applica. tions are rather briefly described.

The articles differ considerably in their comprehensiveness, and in several cases go much beyond the declared aim of the series - to provide critical and useful information for graduate students and also investigators needing to use a particular type of technique.

Two more volumes of this useful series are promised, to deal mainly with certain electrophysiological techniques and types of apparatus. It is to be hoped that these will not be delayed too long. J. A. V. ButLer 